\title{
Responsibility as a virtue
}

Final refereed publication text, forthcoming in Ethical Theory and Moral Practice

Author: Garrath Williams

Affiliation: Department of Philosophy, Lancaster University

\begin{abstract}
Philosophers usually discuss responsibility in terms of responsibility for past actions or as a question about the nature of moral agency. Yet the word responsibility is fairly modern, whereas these topics arguably represent timeless concerns about human agency. This paper investigates another use of responsibility, that is particularly important to modern liberal societies: responsibility as a virtue that can be demonstrated by individuals and organisations. The paper notes its initial importance in political contexts, and seeks to explain why we now demand responsibility in all spheres of life. In reply, I highlight the distinctively institutional character of modern liberal societies: institutions specify many of the particular responsibilities each of us must fulfil, but also require responsibility to sustain them and address their failings. My overall argument is that the virtue of responsibility occupies a distinctive place in the moral needs, and moral achievements, of liberal societies; and this, in turn, explains why it now occupies such a prominent place in our moral discourse.
\end{abstract}

\section{Keywords}

Responsibility; virtue; agency; institutions; liberalism; accountability 


\title{
Responsibility as a virtue
}

\author{
For Ruth Chadwick
}

\section{Introduction}

Philosophers usually discuss responsibility in connection with praise, blame and punishment. Analysis of responsibility for past actions is often traced back to Aristotle, inviting us to suppose that the concept of responsibility is relatively timeless. A related strand of philosophical discussion dwells on what it is to be responsible, in the sense of being a moral agent. Again, such discussion tends to assume that the concept of responsibility does not need to be situated historically. ${ }^{1}$

It may be surprising, then, to note that the word 'responsibility' is rather modern. The English noun dates back to the end of the eighteenth century, so too its analogues in other European languages. Although the adjective has a longer history, it is only in the nineteenth century that the concept is drawn into philosophical controversies. ${ }^{2}$ Our philosophical discussions pose a puzzle, then. If the cluster of concepts associated with responsibility is as timeless as philosophers usually assume, why should a new word have been coined, and gained such currency? I would like to propose that this puzzle can be answered if we turn to a common use of 'responsibility' that philosophers have

1 Major discussions that combine these approaches include Wallace 1994 and Fischer and Ravizza 1998. An interesting exception to such non-historicist approaches is Williams 1985, for whom blame forms one element of a distinctively modern 'morality system.'

2 A detailed account is given by McKeon 1957, pp. 6ff. As McKeon acknowledges, however, the adjective may be traced back rather further - as early as the thirteenth century in French, and in medieval (legal) Latin in the following century (cf Bovens 1998, p. 23n2). Hobbes, for example, asks whether a member of an assembly may be responsible for its debts or crimes $(1651, \mathrm{ch} .22, \S \S 13$, 15); and John Locke speaks of potential borrowers as 'honest and responsible (1691, pp. 234, 286). 
tended to ignore: responsibility as a moral virtue, for which we praise some people and organisations, while we criticise others for its lack.

My concern in this paper, however, goes deeper than this linguistic coinage, and beyond the connections between responsibility as a virtue and other uses of the term more familiar in philosophical discussion. This paper is written in the belief that responsibility is one of the central virtues of modern liberal societies. It is a virtue that we demand of both people and organisations - speaking of socially responsible corporations, managerial responsibility, individual responsibility and so forth. What is it, then, about our mode of social and political organisation that has made the demand for responsibility so ubiquitous and, as I will also argue, so inescapable?

This is to pose a vast question: my reply is necessarily exploratory, especially because philosophical accounts of liberalism and modernity give no particular prominence to responsibility. Rather than turning to existing theories, therefore, I invoke features of modern liberal societies that are concrete, practical realities for all or most of their members. Nonetheless, I will suggest that two quite abstract points readily follow from these. First, responsibility is a virtue of a social order that is pervasively institutionalised, in a peculiarly self-reflexive manner. Second, this institutional fabric is the condition of our exercising responsibility as well as the reason for the virtue's importance. I have argued elsewhere that liberal political theory tends to give insufficient weight to the institutional character of actual liberal societies (Williams, 2006). Here, by contrast, I pursue a moral claim: that we, the members of these societies, are right to give such pride of place to this virtue.

The paper proceeds as follows. First, I briefly examine the historical emergence of responsibility, and note that this does not explain the non-political character of most contemporary demands for the virtue. Second, I turn to the everyday meaning of responsibility, and offer a schematic account of what is involved in this virtue. I stress, in particular, that it involves responding to a whole host of normative demands, within a field of mutual accountability. However, as the next section points out, this poses a puzzle, in that so many factors work against normative consensus in modern societies and against normative unity in the lives of their members. In the fourth section, therefore, I seek to persuade the reader that we must turn to the institutional character of 
modern societies to explain the possibility of responsibility; and in the final section, that this institutional fabric also renders the virtue of urgent importance to us. In a nutshell: Responsibility is made possible by the successes of liberalism's institutional order; it is necessary both to sustain this order and to address its inevitable failures in achieving all that we demand of it.

\section{The emergence of responsibility}

As indicated, philosophers tend to speak of responsibility as a property of all rational agents ('responsible agency'), or as a matter of holding people accountable for past actions (sometimes termed 'retrospective responsibility'). But there is another use, whereby we praise some people, and not others, as responsible. We also commend some collective agents, such as institutions, as responsible - thus one of the original uses of the adjective: 'responsible government.' In this paper I shall refer most often to the individual case, but also want to keep the collective usage in mind, since it turns out to be rather important for our topic. Accordingly, I shall often use the term 'agent,' to refer to both individual persons and collective bodies.

The word 'responsibility' has a relatively short history. Its most important original use was in political thought and debate, for instance in the Federalist Papers (1787) and Edmund Burke (1796). ${ }^{3}$ Here, responsibility pertains to those who govern or to government itself. The Victorians invented and popularised the notion of "personal responsibility,' a term also taken up in modern Christian ethics, where our personal responsibility before God has been much emphasised. Only in the twentieth century, however, has responsibility become a widely noticed and widely articulated demand. What significance should we attach to the newness of the word, and the fact that the virtue it represents has so quickly become important in so many spheres of our lives?

3 Here I am relying on the citations of the Oxford English Dictionary and McKeon 1957, pp. 23ff. As noted, the adjective does have a longer history. 
There are two plausible directions one might follow, when confronting the prominence of responsibility in modern life. On the one hand, one might suppose that the virtue it names is unlikely to be new. ${ }^{4}$ There are good reasons for thinking that the values we associate with responsibility (reliability, judgment, initiative - more on these in a moment) have always been important. What is new, on this line of thinking, is its discursive importance: and the most obvious construction to place on this is that we can no longer take responsibility for granted - that we now have special reasons to notice its absence, or compelling practical grounds to demand its exercise. On this view, we might suppose that the circumstances of responsibility are enduring, though somehow sharpened by our contemporary situation.

Alternatively, one might opt for a more thorough-going historicism about responsibility. One might argue that our modern emphasis on choice, or our peculiar reflexivity toward all values, institutions and authorities, create distinctive forms of agency. This has refashioned us as subjects (as Foucault had it), and created distinctively modern types of collective agency. As well as suggesting that responsibility has a special connection with modern conditions, it would imply that attributing it to agents in pre-modern conditions (or criticising their lack of it) is anachronistic. Such a thesis raises farreaching questions about the social construction of agents and actions, which are bound to be controversial. 5

Here, therefore, I restrict my claims to terms compatible with the first view. I will not claim that responsibility has not been exercised in former historical periods or in social and political settings radically different from our own. Nonetheless, I think we must take seriously the historical appearance of the concept, and especially its obvious significance to modern societies. The question is how we should explain the former, and whether the latter may be justified. To approach the historical question, I turn briefly to the philosopher who has said most about the history of responsibility, Richard McKeon.

4 Evidently, just the lack of a word to name a moral value is not enough to justify a strongly historicist position. Aristotle, for example, spoke of several virtues that lacked a name in his language.

5 At least so far as individual agency is concerned: it is, I take it, rather easier to see that new forms of collective agency might emerge. 
McKeon was also much taken with the newness of 'responsibility.' He argued that political theorists (not least John Stuart Mill) originally turned to the concept to avoid disputes about 'freedom of the will' and moral motivation, and to deal with issues of greater immediate importance, such as legal and representative accountability. This led to an 'enlarged concept of responsibility' that provides 'a way to discuss moral problems of individual action, political problems of common action, and cultural problems of mutual understanding, without commitment to a single philosophy or to the expression of values traditional in a single culture' (1957: 29f). Thus McKeon emphasises the secular character of responsibility: despite the resonance it also found in Christian ethics, it arose in political contexts of mutual accountability and continues to function in the absence of a single scheme of values. Theoretically speaking, responsibility takes us away from 'moral metaphysics,' toward problems 'found in the circumstances and history in which the concept itself was formed' (1957: 32). ${ }^{6}$

Although this suggestion has not been influential in subsequent philosophical discussion, where questions of moral metaphysics continue to preoccupy, it does not seem unreasonable in itself. For my purposes, the difficulty is that McKeon connects the concept closely with political responsibility and the concerns of political theory. This seems to correspond to important historical usages of the word, its use by Hamilton or Burke, then by Mill or, later again, Max Weber. But why has the term become such an everyday concern? If we start with the political uses, one might speculate that this is related to the emergence of universal suffrage. Yet we most often use the term without particular reference to citizenship and its duties. What we lack, then, ${ }^{7}$ is an account of why this term has gained such widespread currency - to the point where responsibility

Or at least it should: part of McKeon's argument is that we do badly to think of responsibility in terms of the problem of free will. In any case, the question of whether adults of sound mind are responsible by virtue of, say, free will does not help with the question of how some better exemplify responsibility than others, nor with how collective bodies might manifest responsibility.

7 I need to make one central exception, a figure who will be unheard of by most readers. Geoffrey Vickers anticipates much of my argument, being an acute observer of 'two familiar but staggering changes of the last hundred years. One is the escalation of our expectations; the other is the escalation of our institutions' (1973, p. 11). 
has become something that we continually demand of each other, and of the organisations amongst which we live.

\section{What does 'responsibility' involve?}

If we turn to contemporary usage, many connotations of 'responsibility' are clear, even if it is not immediately obvious how they fit together. There is an element of reliability and commitment, of carrying on with something over time. There is a dimension of initiative or judgment: the agent can be trusted with something and to exercise some degree of discretion. There is an obvious point of connection between the virtue and retrospective responsibility, in terms of mutual accountability. This involves a readiness to identify with and answer for past actions or omissions, and to make up for these where they have proved faulty. In each case, we tend to have a particular 'sphere of responsibility' in mind. This certainly includes an agent's previous actions but is typically more forward-looking, to some particular area of care and concern. ${ }^{8}$ This points to yet another use of the word: we sometimes use 'responsibility' as a synonym for obligation. Clearly, the virtue is closely related to conscientiousness in fulfilling one's responsibilities. With some circularity, one might say that responsibility suggests an agent who lives up to her, or its, position within a division of responsibilities and within relations of mutual accountability.

Given this complexity, there are many ways in which one might attempt to define the virtue. According to Max Weber's well-known ethic of responsibility a person (above all, the political actor) 'must bear the (foreseeable) consequences of his actions,' which requires that he be able to face realities 'with inner composure and calm' (1919: 441, 436). ${ }^{9}$ The Oxford English Dictionary defines 'responsible' as 'capable of fulfilling an

8 Thus we may praise someone as responsible in two ways. We may say she is responsible per se. Or we might describe how well she performs a particular role - eg, 'the responsible mother' - and thus refer to a particular sphere of responsibilities.

9 My translation. Weber writes, of course, in terms of Verantwortung and its cognates. In some contexts, as a referee for this journal has argued, this might be translated as 'accountability.' I retain 
obligation or trust; reliable, trustworthy...' Herbert Fingarette writes, 'Responsibility emerges where the individual accepts as a matter of personal concern something which society offers to his concern' (1967: 6). Clearly, each of these definitions captures something important about the virtue. For the purpose of understanding its significance to modern liberal societies, however, I propose to look at it in more schematic terms. The formula I would like to offer is this: responsibility represents the readiness to respond to a plurality of normative demands. These terms will not be of much assistance in judging whether any particular agent has manifested the virtue, as I will discuss in a moment. My claim, however, is that they will help us to see how and why the virtue has become so important to modern societies.

The chief point I would like to highlight consists in the connection between responsibility and plurality - that is, the many different normative demands ('responsibilities,' as well as other requirements and desiderata) that weigh upon us. My basic reason for emphasising plurality is straightforward: in paradigmatic cases where the virtue of responsibility is demanded the situation involves plural demands. For examples: the professional trying to do his best amid various regulations and professional codes, short-term priorities and longer-term goals; or the anxious parent, trying to balance her child's security with concern for its growing independence, juggling those concerns alongside duties in her workplace. Depending on the situation, there may or may not be serious conflict between these demands. But in every case, there remains a need to chart a course of action that will constitute as adequate a response to them as may be possible.

Even as I say this, a straightforward objection may suggest itself. There are plainly simple cases of irresponsibility where an agent fails in a single basic duty, perhaps from sheer selfishness or utter thoughtlessness. (The babysitter who gets too drunk to take proper care of a child, the driver who omits a needed rest-stop.) I believe that we should regard such cases as derivative - that is, although they can be described in the language

the conventional translation because Weber's general concern is with the qualities of character demanded of the politician - above all, a sense of responsibility. 
of responsibility, they represent a simplified usage that omits one of the concept's most central features. Why else, then, should we treat plurality as central to responsibility?

In the first place, it is difficult to make sense of the intimate connection between responsibility and judgment and initiative if we do not emphasise plurality in demands. If we were simply faced with single duties at succeeding points in time, responsibility would be literally too easy for words. The obedient and dutiful child is not yet responsible, at least not until she starts to exercise her own judgment; the well-trained animal never will be responsible. Compared with the agency of children or animals, two distinctive features of adult human agency (and of certain forms of collective agency) are crucial: first, the capacity to move between different frames of reference; second, to respond for past actions and plan future interventions. Moving between different situations, and moving through changing situations: both involve negotiating multiple normative demands. When we praise an agent as responsible we are describing a readiness to exercise judgment and initiative with regard to the (changing, variable, never entirely foreseeable) demands she encounters over time.

A second basis for this plurality lies in the conflicting perspectives that recur in normative judgment. Even in quite simple cases the agent and those around him may differ or be uncertain about each party's various expectations, priorities, duties, and so forth. There will thus be diversity of opinion and even conflict as to what should be done by whom - the more so, as we recall the extended timeframe that each negotiates, and the different fields of activity that each must traverse. (Again, the connection with retrospective responsibility is clear, as others hold us accountable for past actions. So too the connection to responsibility as a synonym for duty - only that ideas about our duties tend to be so multifarious.) Conflicting demands and conflicting interpretations of those demands are the basic stuff of situations where we care about responsibility.

This poses inescapable problems for practical judgment. The responsible agent must negotiate particular, diverse and sometimes conflicting claims. Being concerned to reconcile these demands, she cannot treat all of them uncritically. It is not only that taking claims at face value (that is, as validly construed by those who place them, including oneself) would be a recipe for thoughtlessness. Even more important, in complex, on-going situations the claims upon us are never straightforwardly 
reconcilable. This means that we cannot take them at face value - except at the price of forgetting or ignoring some of those claims. Rather than sheer selfishness or utter thoughtlessness, then, I am suggesting that the most consequential form of irresponsibility consists in simplifying matters by ignoring some normative demands. ${ }^{10}$ We ask that the claims of the self, the claims of others, the claims of the situation all be responded to. Judgment and initiative, imagination and commitment are our resources for discerning and extending what is possible and appropriate by way of response - not just in terms of individual acts, but also courses of action or institutional policies.

A third basis for plurality: the responsible agent finds herself amid many forms of partiality. We are used to associating responsibility with impartiality - one prejudice against responsibility is that it is a cold and impersonal virtue. But it is still true that claims of intimates, friends and family weigh on the responsible person. More important again are the partialities created by our institutional roles and affiliations: a manager is responsible for her employees, a teacher to his students, a club member to fellow members (this is part of what we mean when we speak of an area of responsibility). The responsible person must be a skilled judge of the particular relationships she has to others, the demands that each relationship poses, and the demands that others are entitled to make. The same is true of an organisation, which must constantly take a view as to the legitimacy of the many demands made of it.

Finally, every responsible agent is firmly embedded in a 'non-ideal' context. Things go wrong and situations are complicated. ${ }^{11}$ We can add: agents do wrong and agents are complicated. Part of Weber's well-known 'ethics of responsibility' was that the statesman (or in general, the responsible person) cannot simply rely on 'principles': others' wrong-doing must be dealt with, and this generally involves compromises one would prefer not to make - actions and measures that would not be needed in an 'ideal world' (cf Weber, 1919: 440ff). Certainly, it requires complex judgments about how far

10 This claim might be supported by the many studies of organisational wrong-doing, from Hannah Arendt's study of Eichmann's conscience (1965) to Robert Jackall's study of American corporate life (1988). See further Bovens 1998 on accountability within organisations.

11 As Strawson put it in 'Freedom and Resentment' (1962). 
agents have lived up to particular or general responsibilities, and who should exact what sort of accountability ('hold them responsible'). Responsibility is always a matter of living with agents as they are, as well as what they might become, and doing so in terms of one's particular relationships and responsibilities toward them.

In addition to this emphasis upon plurality, I have also selected some other terms in which to speak of responsibility. First, I think it is helpful to describe the demands upon responsible agents in the loosest terms: hence my term 'normative demands,' rather than, say, responsibilities, duties or 'reasons.' 12 Thinking about matters from the perspective of the agent herself, as well as those she (or it) interacts with, we need to capture all the prima facie claims which people believe should prompt the agent to act or judge in one way rather than another. Such claims upon our attention and concern go wider than many accounts of 'morality' or 'reason,' to include everything that participants or observers feel should matter to an agent's choice. Naturally, these demands may not have the precise force they are felt to have, nor (if consciously articulated) the exact force they are interpreted as having. In some cases such claims may even be entirely factitious. Nonetheless, which of these claims or interpretations should really guide thought and action - this is something the responsible agent must negotiate with those around her.

Second, following the derivation of the word, I speak of 'responding' to demands. This too is very loose. Evidently, what constitutes an adequate or appropriate response is a thoroughly normative matter, and often represents a difficult question of experience and judgment. (Some responses, such as denial or avoidance, are typically components of irresponsibility.) From the perspective of an agent interacting with many other agents, responsiveness to reasons (eg, Wolf 1990, Wallace 1994, Fischer and Ravizza 1998). When we judge an agent to be more or less responsible it seems fair to suppose that she proves more or less responsive to the relevant reasons - indicating another direct connection between the virtue and responsible agency. However, to note this connection is to raise a delicate question, beyond my scope here, as to whether responsible agency comes in degrees, so that human beings may be unequal in their moral capacities. However this may be, our judgments of people as more or less (ir)responsible certainly pronounce some as better than others in negotiating key areas of moral and practical life. 
the question is: Who judges whether a response is fitting? Or: who is authorised to hold the agent to account? And on the other side, it must be part of the responsible agent's task to render account - as to how she has understood the demands upon her, as to how her actions can be taken as adequate or appropriate responses to these. Naturally, these responses need not be articulated: an important part of accountability lies in accepting the force of others' reactions (which, in turn, need not be articulated) and adjusting one's actions or course of action to take account of these. (I make this last point to emphasise that responsibility is firstly concerned with actions, and only secondarily with articulations.)

Finally, I believe it is helpful to think about responsibility in terms of 'readiness' - that is, both willingness and ability. When philosophers speak of 'responsibility' as a basic feature of normal human agency they generally mean something like the capacity to act on the basis of reasons (or, in my looser terminology, to respond to normative demands). When we use the term to praise an agent we are indeed partly concerned with his ability - hence the many variations in the intrinsic capacities of human beings and organisations. (Note, however, that abilities are also relative to the demands and possibilities of situations - as I will stress below, the ability to fulfil any complex task depends very much on one's circumstances.) In addition, we are also concerned with an agent's will to employ his abilities - that is, we are judging the extent to which he perceives and accepts his responsibilities. For our purposes, the phrase 'holding someone responsible' is somewhat misleading, because the virtue of responsibility involves what others can neither compel nor instruct: as Fingarette stressed, responsibility is about acceptance of the demands one faces.

As indicated above, this is to view the virtue in highly schematic terms, to the point where it may seem wholly divorced from particular judgments of whether an agent - be it an individual or a collective - has manifested responsibility. This is deliberate. In any given situation - and especially, as I shall stress in a moment, amid the complexities of life in modern societies - it will be a matter of judgment both broad and deep, as to what demands really weigh upon an agent, and what sort of responses may be possible and appropriate. This question of judgment is fundamental to our subject matter: responsible agents can, and must, judge for themselves and with others. As such, an account of responsibility has to take seriously the capacity of responsible agents to 
judge, and to judge one another. Nonetheless, if there is one thing that theoretical reflection can assert about this process of mutual judgment, it is that a whole host of diverse claims will be made of each agent: the responsible agent must appreciate and weigh these demands, and try as best she (or it) can, to negotiate an appropriate response to them.

\section{A paradox of modern responsibility}

Why is responsibility no longer a distinctively political concern? The first stage of my reply was to examine some features of the virtue of responsibility, underlining above all plurality in the demands to which we expect responsible agents to respond to. Putting the matter slightly differently, we might say that responsibility is concerned with the sheer difficulty of maintaining and fostering human cooperation in the light of a whole range of limiting factors: the resources and attention that each agent can bring to bear, the competing demands on each agent, the diverging perspectives of plural agents, the limited but overlapping spheres of responsibility of different agents, and the complexities of mutual accountability amid non-ideal conduct. It is easy to see that these factors weigh especially heavily in political contexts. It is easy, too - in outline, at least - to see that they enter into the everyday lives of almost all the members of modern liberal societies.

All accounts of modernity allow, even insist, that diversity of expectations and demands is especially marked in contemporary societies. At the widest level we seem to lack the fixed reference points that were present to pre-modern societies: religion, authority, nature, custom. To whom (or what), then, does the responsible agent take herself to be accountable, and on what terms? Moreover, a whole series of demands are placed upon each agent. Plurality is evident not only in the sea of voices announcing their expectations, but also with regard to the sources of those demands - not least, the many roles individuals take on or are landed with. Again, accounts of modern liberal societies agree that our modern situation presents a peculiar absence of fixity. Few are the roles we are born to; characteristically, even the most 'natural' or 'involuntary' roles are subject to loud dispute (what are the claims of family, of ethnicity or nationality, of humanity itself?). Many are the roles we choose: parent, friend, engaged citizen, job- 
holder, professional, and so on. Furthermore, many of these roles invite on-going renegotiation. Both choice and negotiation open up further fluidity, only increasing the plurality of demands upon the actor.

This poses an apparent paradox. It is (one may say) all very well to stress plurality in the demands upon us. But it is equally clear that agents must be able to find some way of negotiating and reconciling this plurality. If an agent - whether a person or an organisation - were to acknowledge a mere sub-set of the demands placed upon her, responsibility would badly fail. Nor can the responsible agent act as if she were the sole authority as to the normative demands that she should honour, or we would lose the vital connection between responsibility and mutual accountability.

In other words: Responsibility looks as if it has become all but impossible, at just that historical moment when we articulated the virtue and began to demand it of our institutions and ourselves. One way of understanding this seeming paradox would be to suggest that we have been driven to notice what has slipped from our grasp. The more plural the demands upon us have become, the more we have felt the need for the virtue which shows us responding to them all, each in its proper measure: thus responsibility's place in political theory from Burke to Weber. As the expectations that modern societies place upon us - or that we place upon one another - have become ever more multifarious, shifting and conflicting, our demand for responsibility has become more widespread, but at the same time more unattainable. Unless there are resources that agents are able to draw on in minimising the plurality of demands upon them and in delimiting the plurality of voices that would hold them to account and judge the adequacy of their responses, then only pessimism will be justified.

Many accounts of the modern age readily concur in such pessimism. Some communitarians - Alasdair MacIntyre is the best-known example - have doubted whether any virtue can be exhibited in an age of such moral fragmentation. The paradox that meets responsibility is actually the paradox of a society that talks of morality but 
lacks the unity to sustain any ethics at all. ${ }^{13}$ Trenchant critique may also be found among Foucauldian writers, who discern disciplinary forces in our ideals, as elsewhere. Nikolas Rose, for example, writes of 'responsibilisation,' 14 inviting us to suspect that the virtue involves impositions which are far from innocent, and perhaps not even meetable. And although it is only one, rather untheoretical, element in such an argument, the prevalence of chronic stress among so many who work hard to meet all the demands made of them - and which they make of themselves - might offer persuasive evidence for this suspicion.

Other writers may be more optimistic. Some liberals - Rawls is the most prominent discern sufficient overlap in our fundamental values for us to sustain a liberal political settlement. Perhaps one might extend such optimism downwards, to our "politics of everyday life.' In this case, responsibility would still be a task, but not an insuperable one. - While I would like to share some of this optimism - and must do, to sustain my overall argument about the rightful place of responsibility in our societies - I doubt that we can address this paradox of responsibility in terms of supposedly shared values, that prevent us from making demands of one another that are irreconcilable in their plurality. Responsibility is the moral child of highly differentiated, socially plural societies, and these societies give rise to astonishingly variegated and relentlessly specific moralities among their members. Even if there were some fundamental agreement in underlying values, this would hardly answer to the fragmentation in the actual moralities that we each encounter and act on in our daily lives.

My own view, then, is that we cannot deny the lack of the fixity and coherence that distinguish our modern moral situation. Against more pessimistic perspectives,

13 MacIntyre 1981/4. Bernard Williams has made the related claim that the peculiar degree of reflectiveness of modern societies has lent 'thicker' ethical concepts less currency (1985, pp. 163f). Williams does not make clear the logic behind this contested claim. But it is more natural to think that greater social reflexivity calls not for 'thinner' but for more reflexive moral concepts responsibility being a case in point.

14 Rose 1999, pp. 154f, 214f. As with MacIntyre, my brief comments hint at only a small part of his case. 
however, I think we should see responsibility as one of our most essential and constructive moral responses to this lack. ${ }^{15}$ Nonetheless, to understand how responsibility constitutes a tenable response we must also locate something that unites us - and something much more concrete than any supposed consensus in underlying values. (- Not even a consensus upon the virtue of responsibility: as I have interpreted it, responsibility may mean very different things to different people, depending on the demands we suppose any given agent to face.) In the next section I argue that this unifying factor is the stable, if contested, schemes of cooperation embodied in our modern institutions. That is, to explain the modernity of responsibility, and to show how we might overcome the apparent paradox it poses, we must relate it to our modern institutional fabric. The way in which organisations delimit the plurality of demands upon agents provides the key to our relative success in realising responsibility. At the same time, it explains why responsibility has become so important to us.

\section{What makes responsibility possible?}

My claim is that the central occasion for our discovery - or invention - of responsibility is the peculiarly institutional and peculiarly reflexive character of modern societies - not just in the formal political sphere, but across every field of life. As McKeon argued, a liberal political background is important to the genesis of responsibility, as power comes to be shared in and beyond representative assemblies. But this political origin is no longer evident on a day-to-day basis: we most commonly demand and speak of responsibility without reference to overtly political matters, and most of us bear quite minimal or sporadic political responsibilities. ${ }^{16}$

15 There are obviously many more, but most of these have been more widely recognised, and are more obviously political in character, than responsibility (eg, civic and welfare rights, toleration, or procedural justice).

Of course, many think that our responsibilities in this regard are, or ought to be, greater than liberal theory usually takes them to be. Sympathetic as I am to this line of thought, it does not affect the overall point being made here. 
However, our customary lack of political activity does not mean that we do not possess certain powers. In a liberal democracy it is a matter of course that important powers belong to a wide range of institutions - from schools to parliaments, corporations to charities. More, it is a distinctive feature of these societies, remarked on by almost all theorists, that we take it for granted that all our institutions can and should be remade to suit human wants and interests. Such attempts at change come not just from above (eg, the directives of government) but from below, through the actions of individuals and organisations, usually outside of formal political processes. For examples: citizens may form a new charity to address a particular social concern, or a regulatory agency may alter the liabilities of certain financial institutions.

This self-reflexive web of institutions in turn distributes non-negligible powers to the huge numbers of people occupying roles within it. In this stunningly novel historical situation, the responsibility implied by power has become an intimate and universal concern - of the many vested with such powers, to everyone who is affected by their exercise. Responsibility is a central demand when we are granted significant discretion or power, wherever innovation, change, and fluidity rob practices of fixity, so that our mutual expectations require on-going renegotiation. This need to negotiate a plurality of demands is present to almost every member of our society, and in almost every field of life.

There is obviously much to say about these facets of modern social and political life facets, as I have argued elsewhere (Williams 2006), that are not sufficiently taken account of in contemporary liberal theory. But I think even these very selective comments allow us insights into responsibility omitted in contemporary philosophical discussion - or, indeed, taken as read in applied ethics, when we investigate the particular responsibilities of individuals or organisations. Amid this institutional fabric, a very large number of people are granted highly specific and delimited powers by virtue of the roles they choose or accept. These often include powers to redefine roles and relationships, even to reform institutions. These role-occupants are also granted resources to enable them to achieve certain tasks, as well as to reward them for their efforts. With power, accountability: Roles expose actors to accountability via specific channels, and often involve holding others accountable. Although many such interactions cross the boundaries of particular institutions, as when one agency oversees 
another, or a body provides services to another, they are nonetheless channelled and delimited by institutional frames.

In emphasising the institutional background of this virtue, I mean to argue that responsibility is a moral achievement, but that its basis is not to be found at the level of ideas or beliefs or 'values.' What is central is the moral division of labour created by our institutional fabric. This scheme of cooperation delimits the normative demands upon each of us, by defining particular spheres of responsibility. Given the fluidity, plurality and disagreement associated with normative demands in modern societies, this limitation is crucial. Without it, we would be left in a situation of paralysing uncertainty or desperate decisionism. When institutional fabrics break down, the result is clear to see: unable to respond to all the demands upon them, and deprived of organised channels for mutual accountability, people retreat into the local - closing off moral sensitivity by suppositious boundaries between 'friend' and 'enemy,' insider and outsider. (Similarly, when institutional fabrics are weak or near-absent, as in many international contexts.)

At the same time as limiting the range of demands upon us, of course, our moral division of labour greatly intensifies others. As well as highly specific chains of accountability, agents accept highly specific responsibilities that could not even be conceived of without a very complex scheme of cooperation - from maintaining these railway tracks, to teaching this group of students, to defining the priorities of $m y$ company. Clearly, we are able - morally as well as practically - to attend to these because others have specific responsibilities for other matters, and often to check and counterbalance our own activities. My organisation can focus on profit because they are competing and he is regulating and they are enforcing, and so on.

Of course, some of these realities are not entirely new. Deliberately created bureaucracies, for instance for taxation, are very old indeed. What is new, however, is the ubiquity of these factors, that they impinge in so many ways upon every member of the liberal polity. Everyone is aware of the artificial character of our institutions, and everyone aware of some entitlement, however minimal, to demand or contribute to their reform in the name of her own or others' needs and interests. (Our willingness to apply categories of vice and virtue to our organisations is one reflection of this item of modern 
common sense.) Similarly, we often contest the responsibilities attaching to individual roles. A series of empowerments enable us to do both: the privileges attaching to individual roles and positions; more particular, highly variable membership rights; and not least - overarching legal and citizenship rights. In other words, politically secured rights - freedoms to associate, to found new organisations, to leave particular roles, to speak out - remain central to the operation of this institutional fabric and its successful distribution of powers. Hence the important coincidence between responsibility and the emergence of democratic government, notwithstanding the largely non-political character of most manifestations of responsibility.

\section{What makes responsibility necessary?}

When moral and political philosophy are not idealising the rights and freedoms of modern society, their default mode is critique - a contrast I already drew attention to in opposing possible communitarian and Foucauldian perspectives to an (admittedly naïve) liberalism. In emphasising responsibility I mean to take distance from both tendencies. Striking as our freedoms are, our mutual dependence is still more inescapable. While liberal societies have sufficient failings to think complacency a real danger, failures to recognise these achievements are also common and problematic. The membership of a modern polity makes more extensive, variegated demands of itself than any other community in human history - the rights we are accorded, the material goods available, the powers and opportunities open to most citizens, would stretch the imagination of any previous generation. We achieve this via a division of responsibilities that is without precedent - not only astonishingly complex but also highly reflexive and responsive.

In emphasising the virtue of responsibility, I am suggesting that this constitutes a specifically moral achievement. Despite the many centrifugal forces of modern societies, despite their materialism and inequalities, despite the currency of ideological or self-serving notions of freedom and autonomy - despite all this, it is striking that most of us not only depend on one another but act in ways that allow others to depend on us. Most people take on extensive and demanding responsibilities, and - to their great moral credit - many of them act responsibly, often across all the roles they play. 
They thereby sustain a fabric of relationships and institutions that, for all the costs it may exact of us (- and of some far more than others, of course), channels immense energies toward meeting one another's needs and wants.

Of course, this division of labour is never perfect; sometimes it turns out very faulty indeed. That is to say: if our institutional fabric makes responsibility possible, it also continually demands responsibility of agents. One reason for this, regardless of any organisational gaps or flaws, lies in the essential connections between responsibility, commitment and judgment. However closely our roles and responsibilities are specified, and however tightly accountability is enforced, we still need to act so that others may depend on us, and to exercise initiative in balancing and negotiating the various demands upon us. But there are at least three further respects in which responsibility is always demanded, and which highlight its highly reflexive and mutual character.

I have stressed that responsibility is necessarily connected with mutual accountability. It applies not only as we weigh demands, so as to be able to render proper account of our actions; it also requires that we be prepared to be held accountable for our actions; and further, to hold others responsible for their actions. How do agents become aware of the demands upon them? How do others' expectations of us become expectations of ourselves? How are allocations of power and resources coordinated so that we can fulfil these demands? How is retrospective responsibility constructively apportioned? - Our institutions define roles and relationships, which in turn largely define who should hold whom accountable and in what regards - from the citizen's duty to hold politicians accountable, to the regulatory agency's supervisory tasks, to the employee's need to stand up for her rights. These relations of accountability are, in turn, closely defined in their subject matter, modes of scrutiny, rewards and sanctions. Especially when roles are transgressed, however, it is often systematically unclear who is entitled to hold whom to account and by what channels. In the non-ideal contexts that we always inhabit, formally defined chains of accountability are never the whole story. So it is always possible that failings in others' conduct will require responsible agents to step outside of these.

A broader point relates to the demand that we be alert to responsibilities that fall outside of our roles. I have argued that responsibility is made possible by a highly sophisticated 
moral division of labour, by the separation of different spheres of responsibility. But responsibilities are always liable to fall through the gaps; changing realities are always liable to disrupt existing divisions of responsibility; actual powers may be at some distance from notional responsibilities. Or in other words, if everyone merely 'does their job, 'organisational irresponsibility may still result. In this situation we must all pick up the pieces, look out for unmet responsibilities - without falling into insubordination or otherwise infringing on others' spheres of responsibility. ${ }^{17}$ Roles define and clarify the demands upon us, but they do not exhaust them. Not least, no moral division of labour can mean that the imperatives of basic human decency cease to speak; the responsible agent has these honour to honour, too.

A third, overarching point concerns the definition and allocation of roles. As the responsibility of a role increases, an agent takes more responsibility for allocating responsibilities to others and negotiating his (or its) own proper sphere of responsibility. Managerial and regulatory roles, for example, often involve supervising the adequacy of an organisation's or a sector's moral division of labour; a parliament must reflect on its own responsibilities as a small company need not. How vital these tasks are can be seen when we recall that agents need to be faced with a manageable plurality of demands. One of the most common sources of irresponsibility, I have been suggesting, is the overloading of agents, presenting them with unmeetable or incompatible demands. Here, the temptation, even necessity, is to drop certain demands - to cut moral or procedural corners, to ignore demands not backed by compelling or short-term forms of accountability. ${ }^{18}$ And indeed, much suggests that many agents are overwhelmed by the plurality of demands upon them - to meet the targets, respect their subordinates, honour the law, and so on. Certainly, we are familiar enough with the irresponsibility that results; so too, with how one agent's irresponsibility can set off a chain reaction in or beyond an organisation. In this situation, responsibility is continually demanded - not just of those who supervise and manage, but also of each role occupant - in assessing the extent to which roles are manageable and responsibilities properly allocated.

See Bovens 1998 on individual responsibilities within organisations. problem is Chester Barnard 1937, pp. 263ff. More recently, see O'Neill 2002. 
The greater the extent to which a given role places one or more of these demands, the greater the responsibility inherent in the role. Equally, we might say that the better an agent fulfils each of the dimensions of responsible activity just described, the more she, or it, can truly be described as responsible.

One final remark. What I have said may seem incautiously optimistic concerning the division of powers and responsibilities within modern societies - as if it were relatively straightforward for most of us to meet the many different demands upon us. I think most readers will agree that our experience is much more ambivalent that this: that responsibility often makes considerable demands of us, sometimes even impossible ones. In the previous section I meant to indicate how our societies are relatively successful in channelling demands and modes of accountability; in this section, to argue why such success is always partial and sometimes parlous. Precisely because our institutions are imperfect, in their divisions of responsibilities as in other regards, is the responsibility of individual and collective agents so badly called for - in enforcing demands that others might neglect, in meeting demands that would otherwise go unenforced, in noticing demands that fall through the organisational gaps.

\section{Conclusion}

In part, my task has been to explain the modernity of responsibility. More important, however, I have wanted to justify the importance we attach to it, and to locate it among the moral achievements of modern liberal societies. I have not denied that there may be a basis for talking about responsibility wherever human beings bring their concern and initiative to bear on their situation. Philosophers, of course, have always had reason to enquire into the moral agency that is a precondition of this concern, and into the responsibility for past actions that belongs to our agency. We have seen that the virtue of responsibility, in turn, depends on basic features of our moral agency - to move between different frames of reference, between past and future; likewise, it involves answering to others for failures to fulfil our responsibilities. But I also hope to have shown how people in modern societies have more reason to demand the virtue of responsibility of one another than those in any previous historical period: so extensive, 
so variegated, so fluid are the demands we make of ourselves, of one another, of our organisations.

I have discussed the virtue of responsibility in very abstract terms, as the readiness to respond to a plurality of normative demands. This may be discomforting in at least two respects. In the first place, as I stressed above, it leaves a great deal open: which demands are valid, which responses appropriate? - I have suggested that a philosophical account of responsibility may abstain from closer judgment of these questions. To speak of 'responsible agents' presupposes that those agents are able to judge, and that where they fail to judge rightly, that other agents are qualified to judge this and hold them responsible. I have left a great deal open because so much is the prerogative of responsible agents themselves.

We might also feel some discomfort for a second, rather different reason. My argument has linked an agent's capacity to manifest responsibility to particular, contingent conditions of society and politics. This implies, then, that responsibility may fail, despite an agent's own best intentions. A will to respond to the plurality of normative demands faced is, I have suggested, not enough: there must also be ability. This is partly a question of the capacities an agent brings to the situation: an individual's imagination, perseverance, judgment and so on; an organisation's resources, flexibility, managerial capability and so forth. But to be able to manifest responsibility also requires the cooperation of one's circumstances; thus the crucial role of modern institutions in delimiting spheres of responsibility and defining relations of accountability. This vulnerability of responsibility to circumstances seems to me appropriate. The virtue of responsibility emerges from our accountability to, and dependence on, one another. Where mutuality fails, then, no surprise that responsibility falters too. In other words: responsibility is not quite the property of an individual that we may think of when we speak of a virtue. Responsibility reveals not only our material and organisational interdependence upon each other, but also, I should like to say, our moral interdependence.

A final point is also striking. Unlike many other virtues, responsibility is a virtue of collectivities as well as individuals. Despite the profound differences between individual and collective agency, about which I have been able to say nothing here, 
there is a remarkable symmetry: almost everything that one can say about the responsible person can be said of the responsible organisation. I have argued that the responsible organisation and the responsible individual depend profoundly on one another, by virtue of the roles that both create and both fulfil. Both, in turn, depend upon a wider fabric of responsible institutions, that involves networks of accountability and divisions of responsibilities. The symmetry between responsibility as individual and organisational virtue reflects this mutual dependence of individual and collective, when responsibility is manifested among us.

\section{Acknowledgements}

I would like to thank the European Academy Bad Neuenahr-Ahrweiler for its generous support during the writing of this paper, and the Centre for Ethics, Philosophy and Public Affairs at the University of St Andrews for its support during the initial research. For comments I would like to thank audiences at Lancaster University, the European Academy and the Philosophy Club at Purchase College, State University of New York, as well as: David Archard, Margaret Canovan, Ruth Chadwick, Sean Crawford, Robin Downie, John Foster, Carl Friedrich Gethmann, Jorge Guerra González, Morris Kaplan, Onora O’Neill, Darius Rejali, Doris Schroeder, Udo Schuklenk and William Torbert, as well as two anonymous referees for this journal.

\section{References}

Arendt, H. (1965). Eichmann in Jerusalem, revised edition. (Harmondsworth: Penguin)

Barnard, C. (1938). The Functions of the Executive. (Cambridge MA: Harvard University Press)

Bovens, M. (1998). The Quest for Responsibility: Accountability and Citizenship in Complex Organisations. (Cambridge: Cambridge University Press)

Downie, R. S. (1964). Social Roles and Moral Responsibility. Philosophy, 39, no. 147, 29-36

Emmet, D. (1966). Rules, Roles and Relations. (London: Macmillan)

Fingarette, H. (1967). On Responsibility. (New York: Basic Books)

Fischer, J. M. \& Ravizza M. (1998). Responsibility and Control: A Theory of Moral Responsibility. (Cambridge: Cambridge University Press) 
Hobbes, T. (1651). Leviathan: or the Matter, Form and Power of a Commonwealth Ecclesiastical and Civil. (Various editions)

Jackall, R. (1988). Moral Mazes: The World of Corporate Managers. (New York: Oxford University Press)

Locke, J. (1691). Some Considerations of the Consequence of the Lowering of Interest and Raising the Value of Money. (In Kelly, P. H. (Ed), Locke on Money, vol. 1. Oxford: Clarendon, 1991.)

MacIntyre, A. (1981/4). After Virtue: A Study in Moral Theory, 2nd edition. (Notre Dame IN: University of Notre Dame Press)

McKeon, R. (1957). The Development and the Significance of the Concept of Responsibility. Revue Internationale de Philosophie, 11, no. 39, 3-32

O'Neill, O. (2002). Called to Account. Lecture 3, BBC Reith Lectures 2002: A Question of Trust, www.bbc.co.uk/radio4

Rose, N. (1999). Powers of Freedom: Reframing Political Thought. (Cambridge: Cambridge University Press)

Strawson, P. (1962). Freedom and Resentment. (In his Freedom and Resentment and other Essays. London: Methuen, 1974.)

Wallace, R. J. (1994). Responsibility and the Moral Sentiments. (Cambridge MA: Harvard University Press)

Weber, M. (1919). Politik als Beruf [Politics as a Vocation]. (In Gesammelte Politische Schriften. Potsdamer Internet-Ausgabe, www.uni-potsdam.de/u/paed/pia/index.htm)

Williams, B. (1985). Ethics and the Limits of Philosophy. (London: Fontana Press/Collins)

Williams, G. (2006). "Infrastructures of responsibility": the moral tasks of institutions. Journal of Applied Philosophy, 23, 207-221

Wolf, S. (1990). Freedom Within Reason. (New York: Oxford University Press) 